\title{
Accumulation of 8-Oxoguanine in Liver DNA During Hyperoxic Resuscitation of Newborn Mice
}

\author{
YNGVE SEJERSTED, ANNE L. AASLAND, MAGNAR BJØRÅS, LARS EIDE, AND OLA D. SAUGSTAD
}

Department of Pediatric Research [Y.S., A.L.A., O.D.S.], Centre for Molecular Biology and Neuroscience [M.B., L.E.], Institute of Medical Microbiology [M.B.], and Institute of Clinical Biochemistry [M.B., L.E.], University of Oslo, Oslo University Hospital Rikshospitalet, Oslo NO-0027, Norway

\begin{abstract}
Supplementary oxygen during resuscitation of the asphyxiated newborn is associated with long-term detrimental effects including increased risk of childhood cancer. It is suspected that the resuscitation procedure results in accumulated DNA damage and mutagenesis. Base excision repair (BER) is the major pathway for repair of premutagenic oxidative DNA lesions. This study addresses DNA base damage and BER in brain, lung, and liver in neonatal mice (P7) after hyperoxic resuscitation. Mice were randomized to $8 \%$ oxygen or room air for $60 \mathrm{~min}$ in a closed chamber and subsequent reoxygenation with $100 \%$ oxygen for 0 to $90 \mathrm{~min}$. During this treatment, 8-oxoguanine accumulated in liver but not in lung or cerebellum. We observed a linear relation between 8-oxoguanine and reoxygenation time in liver DNA from hypoxic animals $(n=28 ; B=$ $0.011[0.001,0.020] ; p=0.037)$. BER activity was not significantly changed during resuscitation. Our data suggest that after hypoxia, the capacity for immediate repair in liver tissue is inadequate to meet increasing amounts of DNA damage. The duration of supplementary oxygen use during resuscitation should be kept as short as justifiable to minimize the risk of genetic instability. (Pediatr Res 66: 533-538, 2009)
\end{abstract}

$I^{n}$ $\mathrm{n}$ the transition from intra- to extrauterine life, the fetus is challenged by a sudden surge in oxygen partial pressure. Rapid alteration of physiological processes is required, but $\sim 10 \%$ of newborns need assistance to begin breathing and $1 \%$ demand extensive resuscitation (1). Administration of hyperoxic gas has been widely used to reestablish normoxia and presumably ensure a vigorous resuscitation. Meta-analyses indicate that this practice may increase mortality $(2,3)$.

Exposure to hypoxia produces higher levels of reactive oxygen species (ROS) in the newborn, and a further increase is seen if resuscitation is performed with hyperoxic gas (4). We have previously provided evidence that markers of DNA oxidation in urine show a dose-dependent increase with graded inspiratory fractions of oxygen (5). Direct damage to DNA by ROS formed in vivo is probably a key event to development of malignant disease, and the base excision repair (BER) pathway plays an important role in disease protection $(6,7)$. Notably, neonatal exposure to supplementary

Received April 21, 2009; accepted July 15, 2009

Correspondence: Yngve Sejersted, M.D., Department of Pediatric Research, University of Oslo, Oslo University Hospital Rikshospitalet, Oslo NO-0027, Norway; e-mail: yngve.sejersted@rr-research.no

Supported by the Research Council of Norway (NevroNor), the Norwegian Cancer Society (Ragnvarda F. Soervik and Haakon Starheim's Foundation), and the Laerdal Foundation for Acute Medicine. oxygen during resuscitation has been associated with an increased risk of childhood leukemias and cancer $(8,9)$.

Exposure of DNA to ROS results in oxidized bases, apurinic/apyrimidinic (AP) sites, and single-strand breaks, all lesions that are handled mainly by a multistep process in the BER pathway (6). In the first step of the repair pathway, lesions are recognized and removed by specific DNA glycosylases, leaving an abasic site, which is acted upon by an intrinsic AP lyase activity in the DNA glycosylase or by a separate AP endonuclease. The resulting strand break is processed by lyases and/or nucleotidases removing the sugarphosphate backbone, and the gap is filled and resealed by DNA polymerases and ligases, respectively.

8-oxoguanine (8-oxoG) is one of the major DNA lesions formed from ROS. Guanine has a low oxidation potential and is readily oxidized to 8 -oxoG. The base modification is highly mutagenic as it may cause GC to TA transversions if not recognized and repaired (7). Removal of 8-oxoG is mainly exerted by the enzyme 8-oxoguanine-DNA glycosylase (OGG1) (10), and a deficiency in this enzyme leads to an age-dependent accumulation of 8-oxoG in mice (11). DNA glycosylases display partially overlapping substrate specificities and may act as backup for each other. The MutY homolog (MUTYH) excises adenine (A) from 8-oxoG:A mismatches when OGG1 has failed, and deficiencies in both these DNA glycosylases result in a strong predisposition to lung and ovarian tumors and lymphomas (12). Oxidized pyrimidines such as 5-hydroxycytosine (5-ohC) may also arise in DNA from exposure to ROS and are acted upon by endonuclease III homolog (NTH1) (13). Deamination of cytosine forms uracil (U), which can be removed by the four DNA glycosylases uracil-DNA glycosylase (UNG), single-strand selective monofunctional uracil-DNA glycosylase (SMUG1), thymine-DNA glycosylase (TDG), and methyl-binding domain protein 4 (MBD4) (14). Repair of AP sites, which are highly mutagenic and cytotoxic because DNA replication can result in either double strand breaks or misincorporations, starts with the actions of an AP endonuclease (6). DNA glycosylases show widespread but differential expression, presence, and incision

\footnotetext{
Abbreviations: 5-ohC, 5-hydroxycytosine; 8-oxodG, 8-oxo-2'-deoxyguanosine; 8-oxoG, 8-oxoguanine; AP, apurinic/apyrimidinic; BER, base excision repair; dG 2'-deoxyguanosine; OGG1, 8-oxoguanine-DNA glycosylase; ROS, reactive oxygen species; THF, tetrahydrofuran; $\mathbf{U}$, uracil
} 
activity, suggesting important age dependent roles both in brain (15) and liver tissue (16).

To better understand the pathogenic outcome after treatment of the newborn, we explored the effect of hyperoxic resuscitation on oxidative DNA damage and BER in an in vivo model of the acidotic neonate. Newborn mice were exposed to hypoxia to produce metabolic acidosis. We provide evidence that while capacity for the initial steps of BER seems unchanged, 8-oxoG increases in liver tissue during resuscitation with $100 \%$ oxygen. This accumulation of premutagenic lesions indicates a vulnerability to hyperoxic gas in the asphyxiated newborn.

\section{MATERIALS AND METHODS}

Animals. Experiments were approved by the National Animal Research Authority (NARA) in Norway. Mice were housed and handled in accordance with the European Council Directive 86/609/EEC. C57BL/6J mice were stabled and bred at $24^{\circ} \mathrm{C}$ on a 12:12-h light/dark cycle with access to a diet of pellets and water ad libitum.

Experimental protocol. At $7 \mathrm{~d}$ of age, pups were block randomized within litters to either hypoxemic hypoxia for $60 \mathrm{~min}$ in a lucite chamber containing premixed $8 \%$ oxygen balance nitrogen (Yara, Oslo, Norway) or normoxemia in a chamber containing ambient air. The groups were reunited and exposed to hyperoxic conditions by flushing the chamber with $100 \%$ oxygen. Mice were unanesthesized and unrestrained throughout the experiment. To study the effect of time in $100 \%$ oxygen, mice were exposed for random duration, ranging from 0 to $90 \mathrm{~min}$. Conditions were monitored by sampling of the air and maintained constant by continuous flow of $0.5 \mathrm{~L}$ gas $/ \mathrm{min}$ through the chamber with an open outlet to avoid alterations in pressure. Carbon dioxide levels were kept at $<0.3 \%$. Pups were separated from their dams during the procedure and temperature in the chamber was maintained at $35^{\circ} \mathrm{C}$ by floor heating to avoid confounding from possible effects of hypothermia. As body temperature decreases during hypoxia (17), the temperature was set slightly above thermoneutral range in newborn rodents (18). Experiments commenced between 0900 and $1000 \mathrm{~h}$.

Immediately following experiments, mice were killed by decapitation and rapidly dissected on ice. Organs were removed and split. The right brain hemisphere, the right lung, and two of the four liver lobes were suspended in cold PBS for nuclear extracts, and the other halves were snap-frozen in liquid nitrogen and stored at $-70^{\circ} \mathrm{C}$ for later DNA extraction.

Tissue preparation. All steps were carried out at $4^{\circ} \mathrm{C}$ unless otherwise stated. Preparation of total DNA was performed as follows: frozen tissue was homogenized with OmniTip plastic probes (OMNI International, Marietta, GA). DNA was isolated using the Wizard Genomic DNA Purification Kit (Promega, Madison, WI). Isolated DNA was denatured at $90^{\circ} \mathrm{C}$ for $10 \mathrm{~min}$ and single-strand DNA was hydrolyzed with Nuclease P1 (EC 3.1.30.1, Sigma Chemical Co.-Aldrich, St. Louis, MO) in buffer (500 mM NaAc, $2 \mathrm{mM}$ $\mathrm{ZnCl}_{2}, \mathrm{pH} \mathrm{5.3)}$ at $50^{\circ} \mathrm{C}$ for $60 \mathrm{~min}$. Nucleotides were incubated at $37^{\circ} \mathrm{C}$ for 90 min with FastAP Thermosensitive Alkaline Phosphatase (Fermentas International, Burlington, Canada) in buffer (10 $\mathrm{mM} \mathrm{MgCl}_{2}, 50 \mathrm{mM}$ Tris $\left.\mathrm{pH} 8\right)$, and the resulting nucleosides were stored at $-20^{\circ} \mathrm{C}$ for later composition analysis.

Nuclear extracts were prepared as follows: fresh tissues were resuspended in cold MSHE (0.21 M mannitol, $0.07 \mathrm{M}$ sucrose, $10 \mathrm{mM}$ HEPES pH 7.4, 1 mM EDTA, 1 mM EGTA) and homogenized with a glass pestle and mortar. Homogenized tissue was separated by centrifugation at $2000 \times \mathrm{g}$ for $10 \mathrm{~min}$. Pellets were frozen and thawed. Nuclei were extracted with 2 volumes of hypertonic buffer (20 mM HEPES KOH pH 7.7, $0.5 \mathrm{mM} \mathrm{MgCl}_{2}, 0.42 \mathrm{M}$ $\mathrm{NaCl}, 0.2 \mathrm{mM}$ EDTA, 25\% glycerol, $1 \mathrm{M}$ DTT, and $100 \mathrm{mM}$ PMSF) and separated at $14,000 \times \mathrm{g}$ for $10 \mathrm{~min}$. Supernatants were recovered and protein concentrations measured on a spectrophotometer [BioPhotometer (Eppendorf, Hamburg, Germany)]. Extracts were stored at $-70^{\circ} \mathrm{C}$ for later incision activity assays.

Analysis of oxidized DNA. Isolated genomic DNA from cerebellum, liver, and lung was hydrolyzed and dephosphorylated as described earlier. The nucleosides were separated by HPLC [two serial coupled columns CromSep Inertsil 5 ODS-2, $2 \times(150 \mathrm{~mm} \times 4.6 \mathrm{~mm})$, Crompack] in buffer [10\% vol/vol methanol, water of Milli-Q grade (Millipore), $50 \mathrm{mM}$ sodium acetate $\mathrm{pH}$ 5.0] set at $0.5 \mathrm{~mL} / \mathrm{min}$. 8-Oxo-2'-deoxyguanosine (8-oxodG) was detected with an electrochemical detector (ECD) (Coulochem II, ESA) with a graphite filter protected 5010 analytical cell (ESA, screen electrode $+150 \mathrm{mV}$; analytical electrode $+300 \mathrm{mV})$, and $2^{\prime}$-deoxyguanosine $(\mathrm{dG})$ was measured with a UV detector (UV2000, Thermo Separation Products) set at $254 \mathrm{~nm}$ (19). Data are expressed as the number of 8 -oxodG per $50,000 \mathrm{dG}$ in the same sample.

DNA substrates. Oligonucleotides containing a lesion on a defined position were radioactive phosphor isotope $32\left({ }^{32} \mathrm{P}\right)$-endlabeled with $\mathrm{T} 4$ polynucleotide kinase (PNK) (New England Biolabs, Ipswich, MA) and $\left[\gamma_{-}{ }^{32} \mathrm{P}\right] \mathrm{ATP}$ (Perkin Elmer, Waltham, MA) as previously reported (20). Substrate oligonucleotides contained the 8-oxoG, 5-ohC or U lesions, or alternatively tetrahydrofuran (THF) (an AP site analog), at a distinct position. DNA substrates were prepared by hybridizing substrate oligonucleotides with complimentary oligonucleotides. The sequence of the THF substrate was $\left(5^{\prime}-\right.$ GCTCATGCGCAG[THF]CAGCCGTACTCG-3') with a complementary G opposite the abasic site at position 13. Substrates with 5-ohC and U contained the lesion at position 15 ( $5^{\prime}$-GCATGCCTGCACGG[5ohC/U]CATGGCCAGATCCCCGGGTACCGAG-3') opposite a G. The sequence of the 8-oxoG containing substrate was (5'-GGCGGCATGACCC [8-oxoG]GAGGCCCATC-3') with a complementary C opposite 8-oxoG at position 14.

In brief, DNA was radiolabeled at the $5^{\prime}$ end by incubation for $30 \mathrm{~min}$ at $37^{\circ} \mathrm{C}$, and PNK was deactivated at $80^{\circ} \mathrm{C}$. Complementary oligonucleotides were annealed by heating the samples to $90^{\circ} \mathrm{C}$ for 2 min followed by slow cooling to room temperature. The double-stranded oligonucleotides were purified by $20 \%$ native PAGE and visualized by storage phosphor autoradiography [Typhoon 9410 (Molecular Dynamics, Sunnyvale, CA)]. Radiolabeled substrates were isolated from the gel, eluted in $\mathrm{dH}_{2} \mathrm{O}$, and stored at $4{ }^{\circ} \mathrm{C}$.

Assays for enzyme cleavage of DNA. Incision assays were performed as previously reported (20) to estimate the ability of nuclear proteins to recognize and remove small, non-helix distorting DNA lesions. To determine the linear range of basal incision activity in control animals, dose-dependent titration reactions were performed (Fig. 1). Nuclear extracts were then diluted in buffer until all samples reached an equal protein concentration $( \pm 10 \%)$, and assays were performed with appropriate protein amount for the linear range.

DNA substrates and nuclear extracts were mixed in reaction buffer $(50 \mathrm{mM}$ MOPS pH 7.5, 1 mM EDTA, 5\% glycerol, 1 mM DTT, and ${ }^{32} \mathrm{P}$-labeled DNA duplex, additionally $5 \mathrm{mM} \mathrm{MgCl}_{2}$ for THF containing substrate as AP endonuclease is magnesium dependent) in a total volume of $10 \mu \mathrm{L}$ and incubated for $30 \mathrm{~min}$ at $37^{\circ} \mathrm{C}$. To promote complete strand cleavage at the abasic sites in 8-oxoG and $\mathrm{U}$ substrates, $2.5 \mu \mathrm{L} 0.5 \mathrm{M} \mathrm{NaOH}$ was added. The reaction mixture was heated to $70^{\circ} \mathrm{C}$ for another $20 \mathrm{~min}$ and neutralized with an equal amount of $\mathrm{HCl}$. A 1:1 amount of formamide loading dye was added, and the samples were denatured at $95^{\circ} \mathrm{C}$ for $2 \mathrm{~min}$. The reaction products were resolved in $20 \%$ denaturing polyacrylamide gels and visualized by autoradiography as for the substrates. Incision activity was calculated as for the titration reactions.

Statistical analyses. Statistical analyses were performed using SPSS 15.0. Linear trends were explored using regression analysis; $B$ describes the increase in 8-oxodG per minute resuscitation. Comparisons between the groups were made using $t$ test. Significance was accepted as $p<0.05$. Values are presented as mean \pm SEM unless otherwise stated.

\section{RESULTS}

Characteristics of the model. Six litters comprising 6 to 10 pups each were included, totaling 48 animals. Of these, five died during experiments and one was excluded due to hydronephrosis. There was no significant difference in weight between the groups (ambient air $n=14,4.0 \pm 0.3 \mathrm{~g} v s$ hypoxia $n=28,4.1 \pm 0.2 \mathrm{~g} ; p=0.76)$. A separate experiment was conducted to determine $\mathrm{pCO}_{2}, \mathrm{pH}$, and base excess (BE) in mixed blood after exposure to hypoxia (Table 1). Mean BE was decreased by $13.7 \mathrm{mmol} / \mathrm{L}$. During the 60 -min course of hypoxemia, pups partially compensated a metabolic acidosis by hyperventilating, resulting in hypocapnia. Respiration rate was counted manually before and 10 min after start of hypoxemia and showed a near significant increase $(n=6,194 \pm 3$ vs $207 \pm 4 ; p=0.058$ by paired-samples $t$ test).

Dose-dependent increase in oxidative DNA damage from resuscitation with $100 \%$ oxygen. We measured 8-oxodG in total DNA. Resuscitation with $100 \%$ oxygen produced $\sim 25 \%$ increase in 8-oxodG levels in liver DNA after 90 min resuscitation. The increase was time dependent and displayed a 

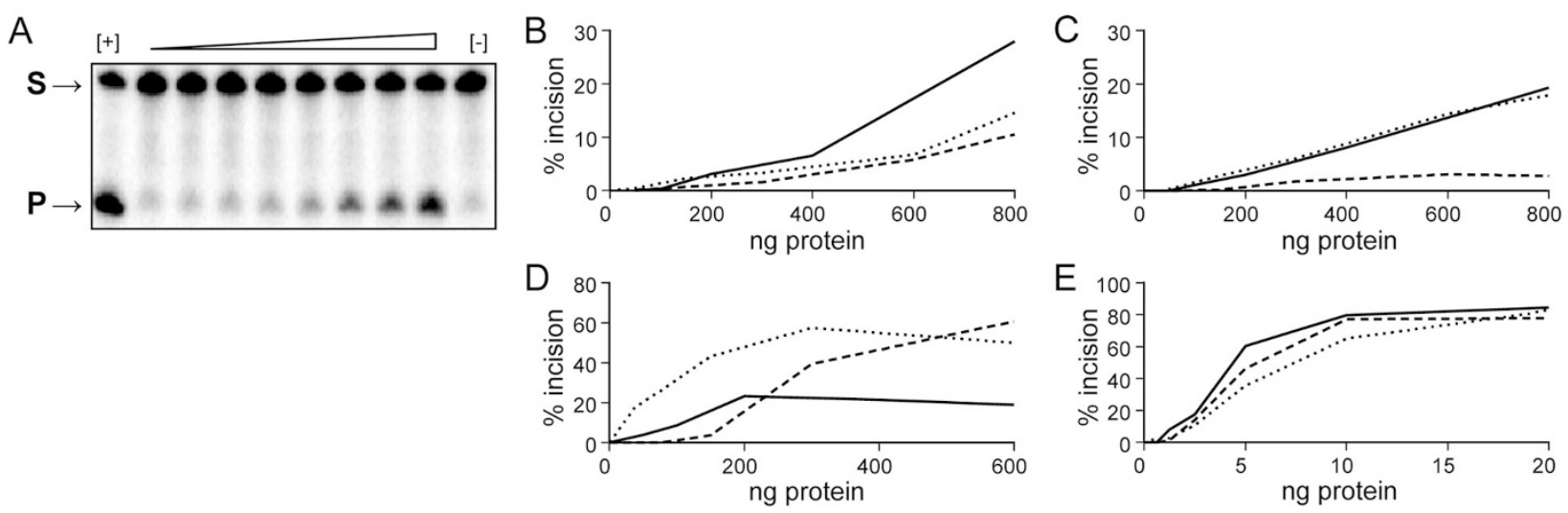

Figure 1. Determination of linear reaction range for incision activity. (A) Typical titration experiment exemplified by incision activity in nuclear extract from lung on 5-ohC substrate. Negative and positive controls indicated. S, substrate; P, cleavage product. (B-E) Titration curves for nuclear extracts from brain (- - ), liver $(\cdots)$, and lung (-) incising $(B)$ 8-oxoG substrate, $(C)$ 5-ohC substrate, $(D)$ Uracil substrate, and $(E)$ AP-site substrate. Incision activity was calculated as the amount of radioactivity in the band corresponding to the damage specific cleavage product over the total radioactivity in the lane using the ImageQuant TL Version 2003.02 (Amersham Biosciences) software. The lower detection limit for incision is $\sim 1 \%$. Curves will flatten due to interference with repair from proteins with nonrepair capacities in nuclear extracts.

Table 1. Whole blood analysis after exposure to $8 \%$ oxygen for $60 \mathrm{~min}$

\begin{tabular}{lcc}
\hline & \multicolumn{2}{c}{ Mean \pm SEM } \\
\cline { 2 - 3 } & Ambient air, & Hypoxia, \\
& $n=5$ & $n=6$ \\
\hline $\mathrm{pH}^{*}$ & $7.42 \pm 0.01$ & $7.36 \pm 0.02$ \\
$\mathrm{BE}(\mathrm{mmol} / \mathrm{L}) \dagger$ & $4.2 \pm 1.1$ & $-9.4 \pm 1.6$ \\
$\mathrm{PCO}_{2}(\mathrm{kPa}) \dagger$ & $6.0 \pm 0.2$ & $3.5 \pm 0.2$ \\
\hline
\end{tabular}

$* p<0.05$ by $t$ test.

$\dagger p<0.001$ by $t$ test.

significant, linear progression (Fig. 2). Lung and cerebellum samples did not show a trend to change. In control animals $(n=14), 8$-oxodG tended to increase less than in hypoxic animals in all tissues during resuscitation, displaying no significant change (cerebellum, $B[95 \% \mathrm{CI}]=-0.014[-0.043$, 0.016]; liver, $B$ [95\% CI] $=0.004$ [ $-0.012,0.019]$; lung, $B$ $[95 \% \mathrm{CI}]=0.000[-0.013,0.012])$. Adjustment for confounding factors (weight, sex, litter size, dams) did not change the significance of the results.

Liver tissue contained lower baseline levels of 8-oxodG per $50,000 \mathrm{dG}(3.88 \pm 0.25)$ compared with lung $(5.86 \pm 0.27)$ and cerebellum $(5.41 \pm 0.78)$ in control animals exposed to ambient air and no resuscitation $(n=8, p<0.001)$. In animals exposed to hypoxia and no resuscitation, 8-oxodG levels were not significantly different from baseline.

BER activities are not altered by resuscitation procedure. DNA glycosylase and AP endonuclease activities were measured in nuclear extracts (Fig. 3). Removal of the base lesions 8-oxoG, 5-ohC, and $\mathrm{U}$ did not display significant changes after resuscitation. A synthetic THF substrate, inert to AP lyase incision, was used to distinguish AP lyase cleavage of abasic sites from AP endonuclease cleavage, which corresponds to APE1 activity. As illustrated in Figure 1, basal AP endonuclease activity was more potent than the glycosylase activity but showed no apparent change after resuscitation with $100 \%$ oxygen, indicating that the observed increase in oxidative damage to liver DNA does not trigger immediate upregulation of repair.

\section{DISCUSSION}

The results presented indicate that newborn mice exposed to hypoxemic hypoxia accumulate 8 -oxoG in a timedependent manner in liver when resuscitated with $100 \%$ oxygen. In rapidly proliferating fetal and neonatal tissue, increased levels of damaged DNA are of particular concern because of the risk of fixating mutations during DNA replication, exacerbating the pathophysiological effects (21). Oxidized purines such as 8 -oxoG are strongly mutagenic because of their preferred base pairing with adenine, and increased levels of this base modification are associated with mutations (10) and early neoplastic changes in the liver (22). We note with interest the previous reports of an association between duration of oxygen treatment and hepatoblastoma incidence in extremely low birth weight infants $(23,24)$. The results reported herein provide a possible explanation for this association.

In support of previous in vitro studies, we found that incision activity for single nucleotide base modifications or abasic sites is not inducible by oxidative damage $(20,25)$. In accordance with data in Figure 1, C57BL/6 mice are reported to have approximately equal OGG1 activity in brain and liver extracts (26). This is somewhat intriguing considering baseline 8-oxoG values in Figure 2, which are higher in the cerebellum, and may be attributed to differential tissue proliferative status with replication- or transcription-associated repair of oxidized lesions in single-stranded DNA (27). Rapid changes in BER activity have been reported after focal cerebral ischemia in adult models and are designated to posttranslational modifications and intracellular redistribution of repair enzymes (28). We would thus expect to detect a change in BER activity if such had occurred in our experiment and 

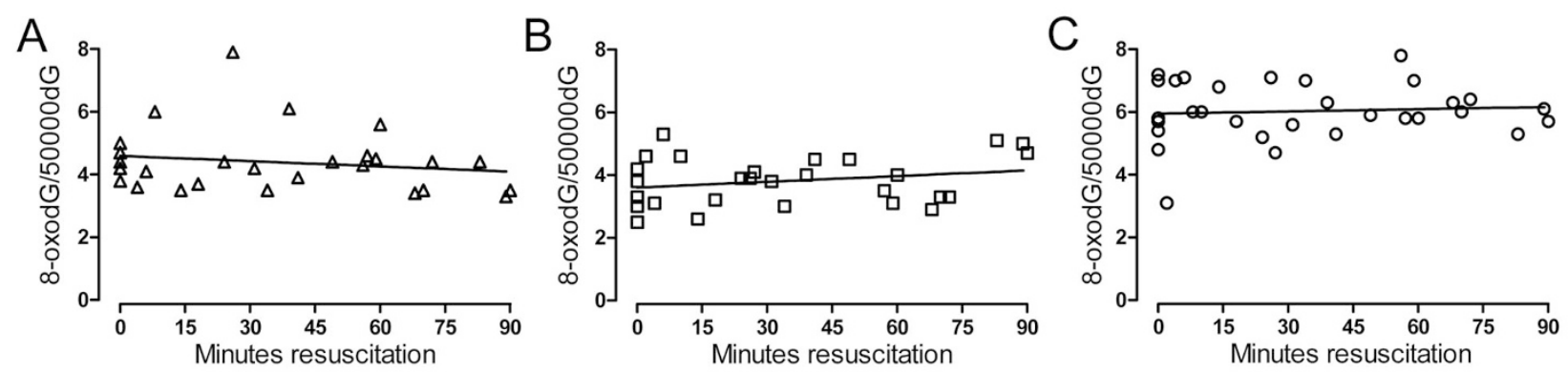

Figure 2. Relation between resuscitation time with $100 \%$ oxygen and 8 -oxodG/50 $000 \mathrm{dG}$ ratio in total DNA $(n=28)$. Regression lines are indicated. $(B)$ Liver DNA displayed a dose-dependent increase in $8-\operatorname{oxodG}(B[95 \% \mathrm{CI}]=0.011[0.001,0.020] ; p=0.037)$, whereas no significant effect of resuscitation was detected in $(A)$ cerebellum $(B[95 \% \mathrm{CI}]=-0.006[-0.021,0.009])$ or $(C)$ lung $(B[95 \% \mathrm{CI}]=0.005[-0.007,0.018])$.
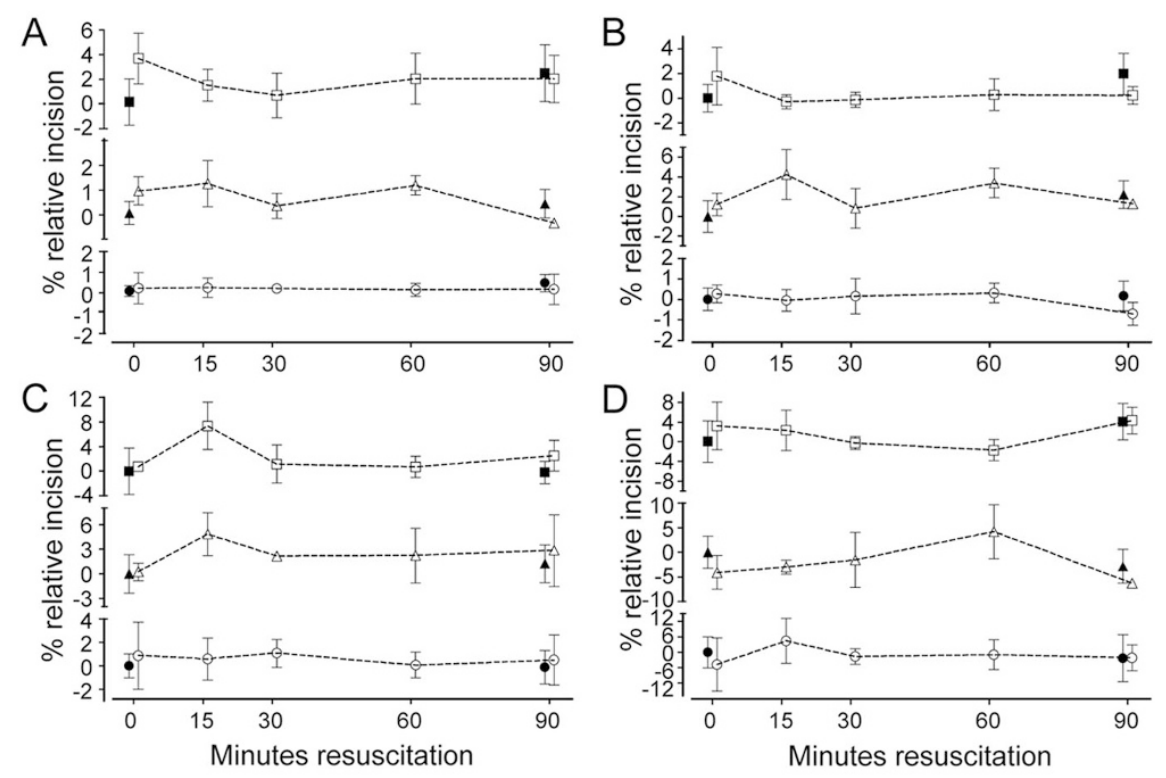

Figure 3. Effect of resuscitation with $100 \%$ oxygen on incision activity in diluted nuclear extracts from brain $(\square)$, liver $(\triangle)$, and lung $(\bigcirc)$ from hypoxic animals and controls $(\boldsymbol{\square}, \boldsymbol{\Lambda}, \bullet)$ not exposed to hypoxia, incising $(A)$ 8-oxoG substrate, $(B)$ 5-ohC substrate, $(C)$ Uracil substrate, and $(D)$ AP-site substrate. Dot and whiskers represent the mean \pm SEM of 3 to 5 independent samples. Values are normalized, the baseline incision activity in control animals not resuscitated is defined as $0 \%$.

speculate that a more severe asphyxiation would provide DNA damage even without subsequent hyperoxia.

In addition to repair of 8-oxoG, we examined the repair activity for pyrimidine modifications and AP sites. The oxidized pyrimidine derivate 5 -ohC can cause $\mathrm{C}$-to- $\mathrm{T}$ transitions (29), whereas deamination of cytosine creates U:G mispairs, which may lead to GC to TA tranversions if not repaired (14). AP sites arising spontaneously or during BER are highly cytotoxic and mutagenic as incorporation of inappropriate bases may occur.

Mechanistically, an increased endogenous production of ROS may be responsible for the observed increase in 8-oxodG in liver. Oxidative stress occurs when the capacity for antioxidant detoxification is exceeded by increasing amounts of ROS. In mammalian cells, a major source of ROS is from energy production in mitochondria, releasing mainly superoxide anion $\left(\cdot \mathrm{O}_{2}{ }^{-}\right)$, hydrogen peroxide $\left(\mathrm{H}_{2} \mathrm{O}_{2}\right)$, and the highly reactive hydroxyl radical $\left(\bullet \mathrm{OH}^{-}\right)$, and formation of these radicals increases both during hyp- oxia and during hyperoxia $(4,30)$. This paradox has been explained by inhibition of cytochorome oxidase in the electron transport chain at low concentrations of oxygen, favoring production of $\cdot \mathrm{O}_{2}{ }^{-}(31)$, although the mechanisms are not fully elucidated. We speculate that the proposed alterations in mitochondrial function during hypoxia further enhance production of ROS upon reoxygenation, which might explain the current findings in hypoxic animals as opposed to controls. Furthermore, the sudden surge in partial oxygen pressure at birth has been reported to increase the amount of 8-oxoG in rat liver DNA (32), indicating a finely tuned equilibrium under physiological conditions. Mitochondrial dysfunction and defective translocation of OGG1, as seen with increasing oxidative stress in older mice (33), may cause disruption and a progressive accumulation of oxidative DNA damage.

To avoid in vitro oxidation during DNA extraction and analysis, we followed a protocol extracting DNA and converting to deoxynucleosides by nuclease P1 and phosphatase treatment avoiding the use of oxidants that may generate 
oxidative lesions. Chromatographic methods for measurement of 8-oxodG are associated with artifactual oxidation, and consensus over the background levels remain to be established, but HPLC-ECD is appreciated as a highly accurate technique for measurement in tissue and cells (34). The modified base can additionally be measured in urine and is used as a biomarker of whole body oxidative DNA damage. Urinary measurements of 8-oxodG are attributed entirely to the repair of DNA damage (35). We have previously shown a dose-dependent relation between graded inspiratory fractions of oxygen during resuscitation of the newborn pig and urinary 8-oxodG (5) but were not able to collect representative samples of urine for comparison with total DNA analysis in this study as the pups frequently had spontaneous miction during experiments.

The pathophysiological responses to hyperoxia, including antioxidant enzyme activity, vary significantly among mouse strains (36). The C57BL/6 is commonly used in studies of DNA damage and repair $(10,26)$, and adult mice display base damage in the lungs when exposed to prolonged hyperoxia (37). Because of the small size of the P7 mouse, there are technical challenges in mechanical ventilation and intensive care, raising a predicament on animal welfare contra the importance of a robust and reproducible model of asphyxia. We performed titration experiments increasing the exposure time to hypoxic gas up to $120 \mathrm{~min}$, resulting in a further, although not significant, decrease of $\mathrm{pH}$ and $\mathrm{BE}$ but obviously increasing mortality. With $60 \mathrm{~min}$ of hypoxia, we experienced a $10 \%$ mortality rate and a decrease in BE satisfying the definition of metabolic acidosis. Because of hypocapnia produced by hyperventilation, systemic $\mathrm{pH}$ will display merely small changes in this model (38).

To our knowledge, there has been no study measuring the effect of supplementary oxygen on oxidative damage and repair in an in vivo neonatal model. Our data suggest that oxidative DNA damage arising after hypoxia and resuscitation with hyperoxic gas is effectively prevented or removed by the normal BER capacity in brain and lung, whereas in liver, an increased oxidative stress load is not met by up-regulation of BER activity. We conclude that while BER activity seems unchanged, there is a dose-dependent association between liver damage and the duration of exposure to hyperoxic gas. Further studies should be conducted to determine whether this vulnerability is differential and age dependent. We are currently cross-breeding specific DNA glycosylase knockout mice aiming for a model deprived of all repair of oxidized DNA lesions to further address the impact of asphyxia and resuscitation on long-term outcome. Although this study has a short duration and conclusions for long-term effects should be drawn with caution, we recommend the use of supplementary oxygen should be limited to justifiable proportions to minimize the risk of detrimental effects.

Acknowledgments. We thank Rune J. Forstrøm for technical assistance with HPLC measurements and Amund Ellingsen for sharing his valuable lab experience.

\section{REFERENCES}

1. International Liaison Committee on Resuscitation 2005 International Consensus on Cardiopulmonary Resuscitation and Emergency Cardiovascular Care Science with Treatment Recommendations, Part 7: Neonatal resuscitation. Resuscitation 67:293-303

2. Saugstad OD, Ramji S, Vento M 2005 Resuscitation of depressed newborn infants with ambient air or pure oxygen: a meta-analysis. Biol Neonate 87:27-34

3. Tan A, Schulze A, O'Donnell CP, Davis PG 2005 Air versus oxygen for resuscitation of infants at birth. Cochrane Database Syst Rev CD002273

4. Kutzsche S, Ilves P, Kirkeby OJ, Saugstad OD 2001 Hydrogen peroxide production in leukocytes during cerebral hypoxia and reoxygenation with $100 \%$ or $21 \%$ oxygen in newborn piglets. Pediatr Res 49:834-842

5. Solberg R, Andresen JH, Escrig R, Vento M, Saugstad OD 2007 Resuscitation of hypoxic newborn piglets with oxygen induces a dose-dependent increase in markers of oxidation. Pediatr Res 62:559-563

6. Maynard S, Schurman SH, Harboe C, de Souza-Pinto NC, Bohr VA 2009 Base excision repair of oxidative DNA damage and association with cancer and aging. Carcinogenesis 30:2-10

7. Bjelland S, Seeberg E 2003 Mutagenicity, toxicity and repair of DNA base damage induced by oxidation. Mutat Res 531:37-80

8. Naumburg E, Bellocco R, Cnattingius S, Jonzon A, Ekbom A 2002 Supplementary oxygen and risk of childhood lymphatic leukaemia. Acta Paediatr 91:1328-1333

9. Spector LG, Klebanoff MA, Feusner JH, Georgieff MK, Ross JA 2005 Childhood cancer following neonatal oxygen supplementation. J Pediatr 147:27-31

10. Klungland A, Rosewell I, Hollenbach S, Larsen E, Daly G, Epe B, Seeberg E, Lindahl T, Barnes DE 1999 Accumulation of premutagenic DNA lesions in mice defective in removal of oxidative base damage. Proc Natl Acad Sci USA 96:13300 13305

11. Osterod M, Hollenbach S, Hengstler JG, Barnes DE, Lindahl T, Epe B 2001 Age-related and tissue-specific accumulation of oxidative DNA base damage in 7,8-dihydro-8-oxoguanine-DNA glycosylase (Ogg1) deficient mice. Carcinogenesis 22:1459-1463

12. Xie Y, Yang H, Cunanan C, Okamoto K, Shibata D, Pan J, Barnes DE, Lindahl T, McIlhatton M, Fishel R, Miller JH 2004 Deficiencies in mouse Myh and Ogg1 result in tumor predisposition and $\mathrm{G}$ to $\mathrm{T}$ mutations in codon 12 of the K-ras oncogene in lung tumors. Cancer Res 64:3096-3102

13. Eide L, Luna L, Gustad EC, Henderson PT, Essigmann JM, Demple B, Seeberg E 2001 Human endonuclease III acts preferentially on DNA damage opposite guanine residues in DNA. Biochemistry 40:6653-6659

14. Krokan HE, Drablos F, Slupphaug G 2002 Uracil in DNA-occurrence, consequences and repair. Oncogene 21:8935-8948

15. Rolseth V, Runden-Pran E, Luna L, McMurray C, Bjoras M, Ottersen OP 2008 Widespread distribution of DNA glycosylases removing oxidative DNA lesions in human and rodent brains. DNA Repair (Amst) 7:1578-1588

16. Riis B, Risom L, Loft S, Poulsen HE 2002 OGG1 mRNA expression and incision activity in rats are higher in foetal tissue than in adult liver tissue while 8-oxo-2' deoxyguanosine levels are unchanged. DNA Repair (Amst) 1:709-717

17. Bonora M, Gautier H 1987 Maturational changes in body temperature and ventilation during hypoxia in kittens. Respir Physiol 68:359-370

18. Mortola JP, Dotta A 1992 Effects of hypoxia and ambient temperature on gaseous metabolism of newborn rats. Am J Physiol 263:R267-R272

19. Hofer T, Moller L 1998 Reduction of oxidation during the preparation of DNA and analysis of 8-hydroxy-2'-deoxyguanosine. Chem Res Toxicol 11:882-887

20. Rolseth V, Runden-Pran E, Neurauter CG, Yndestad A, Luna L, Aukrust P, Ottersen OP, Bjoras M 2008 Base excision repair activities in organotypic hippocampal slice cultures exposed to oxygen and glucose deprivation. DNA Repair (Amst) 7:869-878

21. Bielas JH, Heddle JA 2000 Proliferation is necessary for both repair and mutation in transgenic mouse cells. Proc Natl Acad Sci USA 97:11391-11396

22. Elchuri S, Oberley TD, Qi W, Eisenstein RS, Jackson RL, Van RH, Epstein CJ, Huang TT 2005 CuZnSOD deficiency leads to persistent and widespread oxidative damage and hepatocarcinogenesis later in life. Oncogene 24:367-380

23. Oue T, Kubota A, Okuyama H, Kawahara H, Nara K, Kawa K, Kitajima H 2003 Hepatoblastoma in children of extremely low birth weight: a report from a single perinatal center. J Pediatr Surg 38:134-137

24. Maruyama K, Ikeda H, Koizumi T, Tsuchida Y, Tanimura M, Nishida H, Takahashi N, Fujimura M, Tokunaga Y 2000 Case-control study of perinatal factors and hepatoblastoma in children with an extremely low birthweight. Pediatr Int 42:492-498

25. Bercht M, Flohr-Beckhaus C, Osterod M, Runger TM, Radicella JP, Epe B 2007 Is the repair of oxidative DNA base modifications inducible by a preceding DNA damage induction? DNA Repair (Amst) 6:367-373

26. Karahalil B, Hogue BA, de Souza-Pinto NC, Bohr VA 2002 Base excision repai capacity in mitochondria and nuclei: tissue-specific variations. FASEB J 16:18951902

27. Dou H, Theriot CA, Das A, Hegde ML, Matsumoto Y, Boldogh I, Hazra TK, Bhakat KK, Mitra S 2008 Interaction of the human DNA glycosylase NEIL1 with proliferating cell nuclear antigen. The potential for replication-associated repair of oxidized bases in mammalian genomes. J Biol Chem 283:3130-3140

28. Luo Y, Ji X, Ling F, Li W, Zhang F, Cao G, Chen J 2007 Impaired DNA repair via the base-excision repair pathway after focal ischemic brain injury: a protein phosphorylation-dependent mechanism reversed by hypothermic neuroprotection. Front Biosci 12:1852-1862

29. Kreutzer DA, Essigmann JM 1998 Oxidized, deaminated cytosines are a source of $\mathrm{C}->\mathrm{T}$ transitions in vivo. Proc Natl Acad Sci USA 95:3578-3582

30. Turrens JF 2003 Mitochondrial formation of reactive oxygen species. J Physiol $552: 335-344$ 
31. Cooper CE, Davies NA 2000 Effects of nitric oxide and peroxynitrite on the cytochrome oxidase $\mathrm{K}(\mathrm{m})$ for oxygen: implications for mitochondrial pathology. Biochim Biophys Acta 1459:390-396

32. Randerath K, Zhou GD, Monk SA, Randerath E 1997 Enhanced levels in neonatal rat liver of 7,8-dihydro-8-oxo-2'-deoxyguanosine (8-hydroxydeoxyguanosine), a major mutagenic oxidative DNA lesion. Carcinogenesis 18:1419-1421

33. Szczesny B, Hazra TK, Papaconstantinou J, Mitra S, Boldogh I 2003 Age-dependent deficiency in import of mitochondrial DNA glycosylases required for repair of oxidatively damaged bases. Proc Natl Acad Sci USA 100:10670-10675

34. Collins AR, Cadet J, Moller L, Poulsen HE, Vina J 2004 Are we sure we know how to measure 8-oxo-7,8-dihydroguanine in DNA from human cells? Arch Biochem Biophys 423:57-65
35. Olinski R, Rozalski R, Gackowski D, Foksinski M, Siomek A, Cooke MS 2006 Urinary measurement of 8-OxodG, 8-OxoGua, and 5HMUra: a noninvasive assessment of oxidative damage to DNA. Antioxid Redox Signal 8:1011-1019

36. Whitehead GS, Burch LH, Berman KG, Piantadosi CA, Schwartz DA 2006 Genetic basis of murine responses to hyperoxia-induced lung injury. Immunogenetics 58:793-804

37. Barker GF, Manzo ND, Cotich KL, Shone RK, Waxman AB 2006 DNA damage induced by hyperoxia: quantitation and correlation with lung injury. Am J Respir Cell Mol Biol 35:277-288

38. Vannucci RC, Towfighi J, Heitjan DF, Brucklacher RM 1995 Carbon dioxide protects the perinatal brain from hypoxic-ischemic damage: an experimental study in the immature rat. Pediatrics 95:868-874 